\title{
Assessment of Family Focused Intervention on Knowledge among Diabetic Clients
}

\author{
Manonmani $\mathrm{K}^{1}$, Kanchana $\mathrm{S}^{2}$ \\ ${ }^{1}$ Professor and HOD, Department of community health nursing, AAB College of nursing, Vandavasi, Tamilnadu, India. \\ ${ }^{2}$ Principal, Omayal Achi college of nursing, Chennai, Tamilnadu, India.
}

Abstract

\section{Background:}

Diabetes mellitus is one of the most common chronic disease worldwide. The low levels of education and poor awareness about the disease have an impact on the health of the people living with diabetes mellitus.

\section{$>$ Aim:}

To assess the need of family focused intervention on knowledge among diabetic clients.

\section{> Methodology:}

Research approach utilized was quantitative research approach. Research design followed was true experimental design. Family focused intervention was the independent variable in the study. Knowledge was the dependent variable. Samples were selected using total enumeration technique. Pre test was assessed using structured interview schedule. Family focused intervention was given after pre test which includes IEC, counseling regarding diet and specific management, demonstration regarding foot care and exercise. Post test was conducted using the same tool.

\section{$>$ Results:}

Comparison of the pre and post test level of knowledge showed that the overall mean knowledge score in the post test was 24.50 and 10.29 in experimental and control group respectively. Comparison between experimental and control group by unpaired ' $t$ ' test, $t=28.03$ revealed that there was a high significant difference between the experimental and control group. The results showed that there was significant improvement in the level of knowledge only in the experimental group. This revealed that family focused intervention was effective among diabetic clients.

\section{$>$ Conclusion:}

Knowledge was improved among experimental group to whom intervention was given. Hence family focused intervention can be incorporated as an integral component of the comprehensive health care services at primary level to enable the diabetic clients to manage the condition and prevent the complications.

\section{INTRODUCTION}

Among the adult population non-communicable diseases are increasing nowadays. Type 2 diabetes mellitus is one of the costly chronic disease worldwide. ${ }_{[1]}$ For the past three decades the prevalence of diabetes has been steadily increasing. Mainly low and middle income countries were affected with diabetes mellitus. Diabetes leads to many complications. It includes blindness, kidney failure, lower limb amputation and other long term consequences. These complications impact significantly the quality of life.[2]

Overall morbidity and mortality were increased due to diabetes complications. The prevalence of diabetes was related to many factors. Early detection and management of these factors is necessary to tackle these issues.[3]

Poor knowledge regarding diabetes was one among the main reason for prevalence of the condition. In low and middle income countries communicable diseases are tackled easily. At the same time non communicable diseases increases the burden of the countries. [4]

In India knowledge and awareness about diabetes among rural population is poor. The main reasons were low literacy rate, decreased awareness towards health care and lack of self-reliance in health. To tackle these important health issue the need for conducting large scale diabetes awareness and education programs was essential.[5]

Individual responsibility are needed to decrease the burden of caregivers. Along with this family support is essential to manage the condition and to prevent the complications. Each family must provide various support such as emotional and economic support to the clients. Proper diabetic diet, medication, follow up, regular health checkup are essential in the management process. Proper counseling also helps to reduce the stress. [6]

There was a need for developing a comprehensive care package which focused to increase the knowledge of diabetic clients through family focused intervention. Hence the nurse researcher created the various nursing care modalities to increase the knowledge among diabetic clients.

Keywords:- Diabetes Mellitus, Family Focused Intervention, Knowledge and Diabetic Clients. 


\section{The Statement of the Problem Was}

A study to assess the need of family focused intervention on knowledge among diabetic clients in selected villages, Thiruvallur district.

\section{Objectives}

- To assess and compare the knowledge among diabetic clients.

- To assess the need of family focused intervention on knowledge among diabetic clients.

- To associate the knowledge scores with selected demographic variables.

\section{Null Hypotheses}

$\mathbf{N H}_{1}$ : There is no significant difference in knowledge among diabetic clients.

$\mathbf{N H}_{2}$ : There is no significant association of knowledge scores with selected demographic variables.

\section{MATERIAL AND METHODS}

Research design: The study design was a true experimental design.

Variables: Knowledge was the dependent variable and independent variable was family focused intervention.

Settings: The study was conducted at Health assessment kiosk villages.

Selection and description of participants: All diabetic clients were considered as target population. Accessible population included diabetic clients those who were available during data collection. Experimental and control group were categorized by cluster randomization. Sampling technique used was total enumeration technique. The sample size was 136 and138 in experimental and control group respectively.

\section{Sample selection criteria}

- Inclusion Criteria

\section{Diabetic clients,}

$\checkmark$ who are under oral medications for diabetes with 2 years of chronicity.

$\checkmark$ who seek diabetes mellitus management services from health assessment kiosk.

$\checkmark$ who are willing to participate in the study.

$\checkmark$ who know Tamil.

\section{- Exclusion Criteria}

Diabetic clients,

$\checkmark$ diagnosed to have other systemic disease and co-morbid conditions.

$\checkmark$ who have attended diabetes management program.

$\checkmark$ who were physically challenged.

$\checkmark$ who have severe sensory or cognitive impairment.

Data collection instrument: Data collection instrument included six components such as general information, diet modification, specific management, exercises, foot care and complications.

Intervention package: Family focused intervention was administered only to the experimental group. It includes general information, diet, specific management, exercises, foot care and complications and prevention. Followed this family counseling was given about diet and specific management. Foot care was demonstrated to the diabetic clients and their family members.

Data collection procedure: Proper approval was obtained from ethical committee and village leaders. After brief introduction about the study informed consent was obtained from participants. Followed this pretest was conducted.

Family focused intervention was given only to the experimental group after the pre test. It included IEC package regarding diabetes mellitus using flashcards which took 45 minutes to 1 hour. Followed this family counseling was given to the diabetic clients and their family members. Diet and specific management was focused in counseling. Foot care which included ten steps was demonstrated to the diabetic clients. Participants were encouraged to practice daily walking for minimum thirty minutes. At $3^{\text {rd }}$ month and $6^{\text {th }}$ month post test was conducted in both experimental and control group.

Statistical methods: Demographic variables were analyzed using frequency and percentage distribution. Mean and standard deviation were used to compare the knowledge within experimental and control group. Paired and Unpaired ' $t$ ' test was used to assess the effectiveness of family focused intervention within and between groups. Comparison of difference in the level of knowledge at pre test, $3^{\text {rd }}$ month and $6^{\text {th }}$ month and association were analyzed by using ANOVA ' $F$ ' test. [7] 


\section{RESULTS}

\begin{tabular}{|c|c|c|c|c|c|c|c|}
\hline \multirow{2}{*}{ S. No. } & Components & \multicolumn{2}{|c|}{ Experimental (n=136) } & \multicolumn{3}{c|}{ Control (n=138) } \\
\cline { 2 - 7 } & Pre test & Post test 2 & $\begin{array}{c}\text { \% of } \\
\text { gain }\end{array}$ & \multirow{2}{*}{ Pre test } & Post test 2 & \multirow{2}{*}{ of gain } \\
\hline 1 & General information & 43.8 & 84.2 & 40.4 & 41.8 & 43.8 & 2.0 \\
\hline 2 & Dietary modification & 43.0 & $\mathbf{9 0 . 2}$ & 47.2 & 40.2 & 43.0 & 2.8 \\
\hline 3 & Specific management & 35.0 & 77.4 & 42.4 & 32.4 & 35.0 & 2.6 \\
\hline 4 & Exercises & 30.2 & $\mathbf{8 3 . 0}$ & 52.8 & 25.6 & 30.2 & 4.6 \\
\hline 5 & Foot care & 28.2 & 74.6 & 46.4 & 23.8 & 28.2 & 4.4 \\
\hline 6 & Complications & 25.6 & $\mathbf{8 0 . 6}$ & 55.0 & 21.2 & 25.6 & 4.4 \\
\hline & Overall & 34.3 & 81.7 & $\mathbf{4 7 . 4}$ & 30.8 & 34.3 & 3.5 \\
\hline
\end{tabular}

Table 1:- Comparison of knowledge components within groups $\mathrm{N}=274$

In the post test the maximum percentage of gain was seen with regard to complications, exercises and dietary modification only in the experimental group. No significant change seen in the control group.

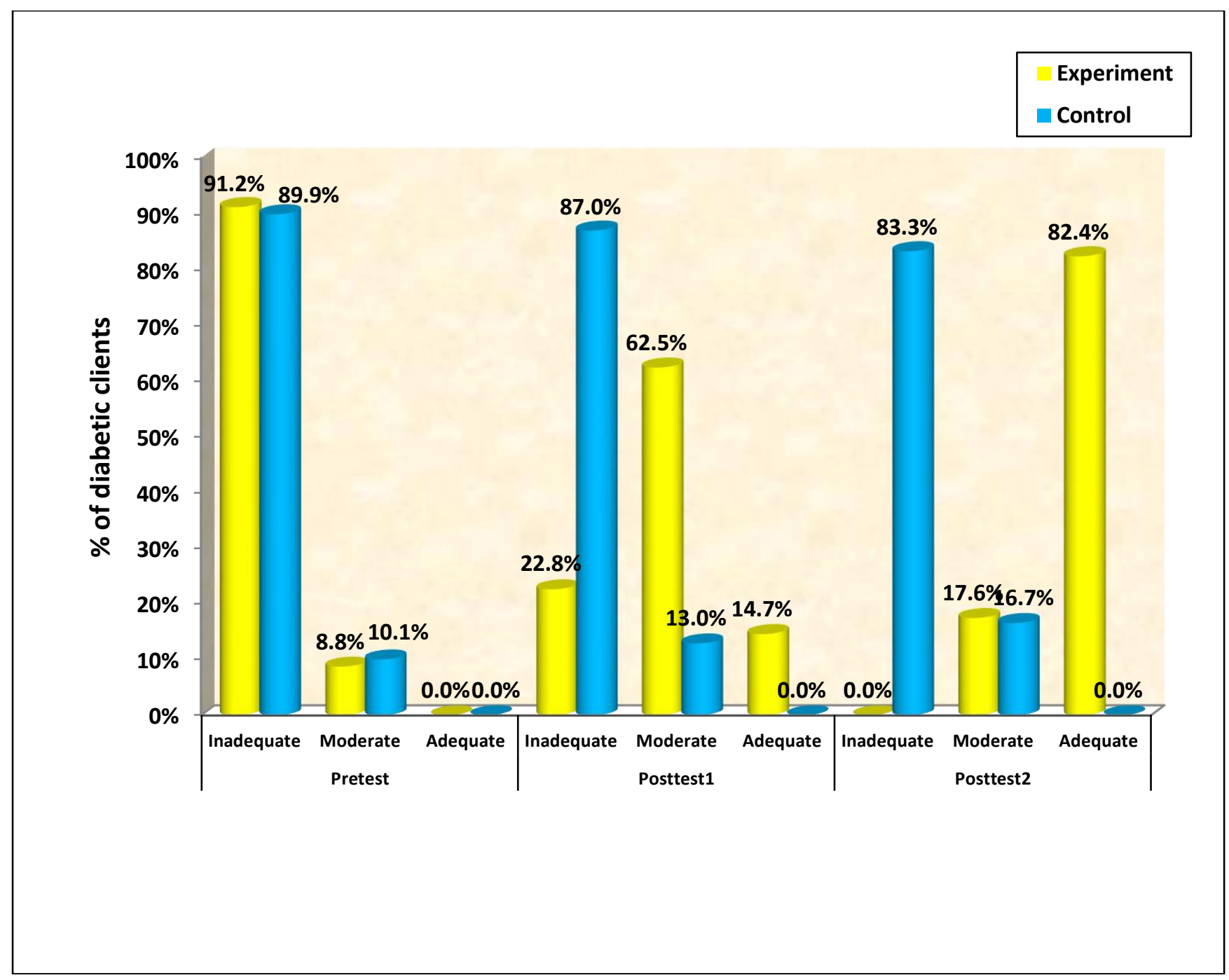

Graph 1:- Overall knowledge among diabetic clients.

In the pre test, majority of them had inadequate knowledge in both the groups. But in post test 1 most of them had moderately adequate knowledge in the experimental group. In the same way in post test 2 also majority of them had adequate knowledge only in experimental group. But samples in the control group remains in the same category such as inadequate knowledge in both post test 1 and 2 . 
ISSN No:-2456-2165

\begin{tabular}{|c|c|c|c|c|c|c|c|c|}
\hline \multirow{2}{*}{ Variable } & \multirow{2}{*}{ Group } & \multicolumn{2}{|c|}{ Pre test } & \multicolumn{2}{|c|}{ Post test 1} & \multicolumn{2}{|c|}{ Post test 2} & \multirow{2}{*}{$\begin{array}{c}\text { Repeated } \\
\text { measures ANOVA } \\
\text { F-test }\end{array}$} \\
\hline & & Mean & S.D & Mean & S.D & Mean & S.D & \\
\hline \multirow{2}{*}{ Knowledge } & Experiment & 9.12 & 4.12 & 18.40 & 4.97 & 24.50 & 4.73 & $\begin{array}{l}F=748.14 \\
p=0.001\end{array}$ \\
\hline & Control & 9.25 & 3.84 & 9.93 & 3.62 & 10.29 & 3.59 & $\begin{array}{c}F=2.66 \\
p=0.08 \mathrm{NS}\end{array}$ \\
\hline
\end{tabular}

*** very highly significant at $\mathrm{p} \leq 0.001 \quad$ NS- Not significant

Table 2:- Comparison of overall knowledge within groups $\mathrm{N}=274(136+138)$

Comparison of overall knowledge within experimental and control group revealed that there was a highly statistical significant difference in the pre and post test in experimental group at $\mathrm{p} \leq 0.001$. But no difference was found in the control group.

\begin{tabular}{|c|c|c|c|c|c|c|c|}
\hline \multirow{2}{*}{ Variable } & \multirow{2}{*}{ Group } & \multicolumn{2}{|c|}{ Pre test } & \multicolumn{2}{|c|}{ Post test 1} & \multicolumn{2}{|c|}{ Post test 2} \\
\hline & & Mean & SD & Mean & SD & Mean & SD \\
\hline \multirow{2}{*}{ Knowledge } & Experimental & 9.12 & 4.12 & 18.40 & 4.97 & 24.50 & 4.73 \\
\hline & Control & 9.25 & 3.84 & 9.93 & 3.62 & 10.29 & 3.59 \\
\hline \multicolumn{2}{|c|}{$\begin{array}{l}\text { Independent } \\
\text { t-test }\end{array}$} & \multicolumn{2}{|c|}{$\begin{array}{l}t=0.45 \\
p=0.65\end{array}$} & \multicolumn{2}{|c|}{$\begin{array}{c}t=16.12 \\
p=0.001^{* * *}\end{array}$} & \multicolumn{2}{|c|}{$\begin{array}{c}t=28.03 \\
p=0.001^{* * *}\end{array}$} \\
\hline
\end{tabular}

$* * *$ very highly significant at $\mathrm{p} \leq 0.001$

Table 3:- Comparison of knowledge between the groups $\mathrm{N}=274(136+138)$

Comparison of knowledge between experimental and control group shows a very high statistical significance in the post test 1 and post test 2 at $\mathrm{p} \leq 0.001$. This proves that family focused intervention was effective in improving knowledge of diabetic clients in experimental group.

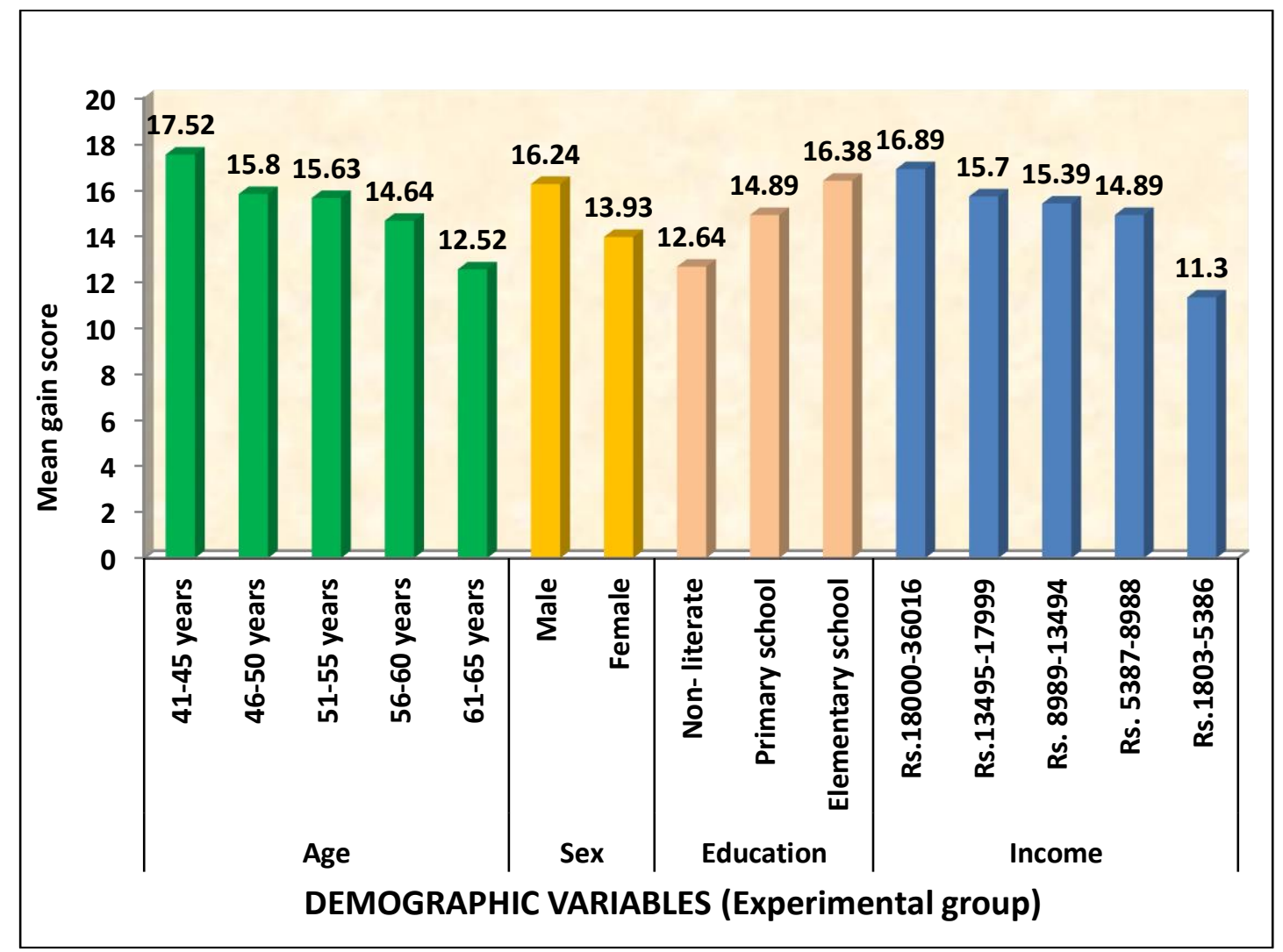

Graph 2:- Association of knowledge score with demographic variables.

The demographic variables such as age, gender, education and family monthly income had statistical significant association with knowledge score at $\mathrm{p} \leq 0.01$ level. 
Thus it infers that 41-45 years aged diabetic clients had more knowledge score. In the same way the knowledge gain score was high among males, who had elementary education and who earned Rs.18000-36016 as family monthly income in the experimental group.

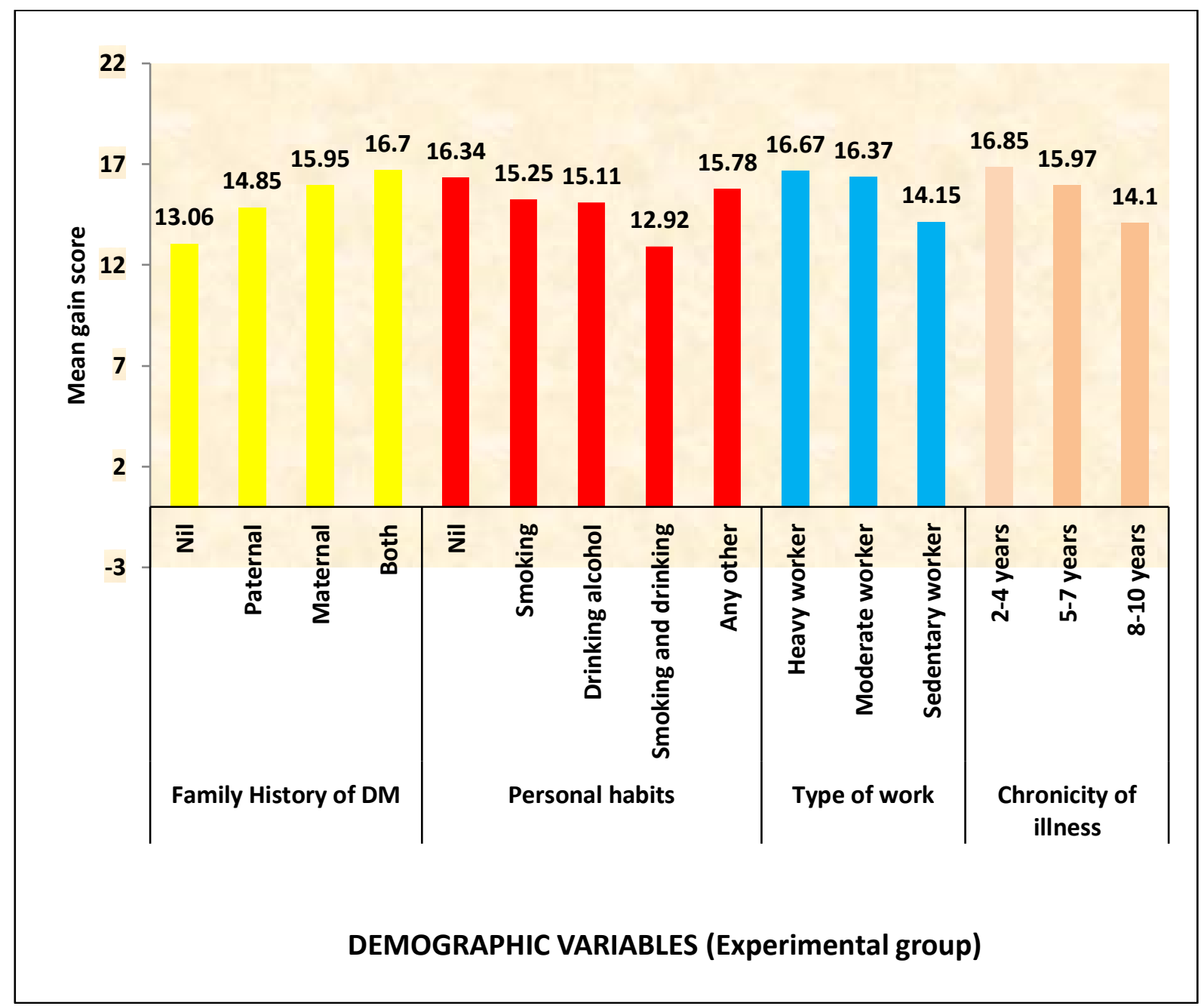

Graph 3:- Association of knowledge score with demographic variables.

The demographic variables such as family history of diabetes mellitus, personal habits, type of work and chronicity of illness had statistical significant association with knowledge score at $\mathrm{p} \leq 0.05$ level.

Thus it infers that knowledge gain score was high among samples who had family history of both paternal and maternal, who were not having personal habits, doing heavy work and having chronicity of illness for 2-4 years.

\section{DISCUSSION}

In the experimental group the overall knowledge percentage was 34.3 and 81.7 in pre and post test respectively. The overall percentage gain score was 47.4. In control group the overall percentage was 30.8 and 34.3 in pre and post test respectively. The overall percentage gain score was 3.5 only. [table 1]
In the pre test majority of them had inadequate knowledge in both experimental and control group [129(94.9\%) and $128(92.8 \%)]$. In the post test 1 it was seen that majority $[96(70.6 \%)]$ of them had moderate knowledge and $8(5.9 \%)$ had adequate knowledge in the experimental group. In the same way in the post test 2 , $35(25.7 \%), 101(74.3 \%)$ had moderate and adequate knowledge respectively.

But in control group majority 125 (90.6\%) had inadequate knowledge in the post test 1 . At the level of post test 2 also, $120(87.0 \%)$ were still in the inadequate knowledge status.[graph 1]

In experimental group the overall pre test knowledge mean score was 9.12 and in post test 1,2 were 18.40 and 24.50 respectively. But in the control group the pre test mean score was 9.25 and in post test 1,2 were 9.93 and 10.29 respectively. 
The ' $F$ ' score in the experimental group $[F=748.14$ at $\mathrm{p}=0.001$ level ] revealed that there was a high statistical significant difference between pre and post test. But the ' $F$ ' score in the control group revealed that there was no statistical significant difference between pre and post test.[table 2]

The overall pre test mean knowledge score was 9.12 in experimental group but in the control group the score was 9.25 . The unpaired ' $t$ ' test value showed there was no significant difference between the experimental and control group in pre test.

In the post test 1 , overall mean knowledge score was 18.40 and 9.93 in experimental group and in control group respectively. The unpaired ' $t$ ' test value of $t=16.12$ showed that there was a statistical significant difference between experimental and control group at $\mathrm{p}<0.001$ level.

In the post test 2, overall mean knowledge score was 24.50 and 10.29 in experimental group and control group respectively. The unpaired ' $t$ ' test value of $t=28.03$ which was greater than the table value at $p=0.001$ revealed that there was a significant difference between the experimental and control group at $\mathrm{p}<0.001$ level. [table 3]

The results revealed that there was statistically significant association of mean differed knowledge score only with the following demographic variables such as age $(\mathrm{F}=3.13, \quad \mathrm{p}=0.02), \quad$ gender $\quad(\mathrm{F}=2.68, \quad \mathrm{p}=0.01)$, education $(\mathrm{F}=5.20, \quad \mathrm{p}=0.01), \quad$ family monthly income $(\mathrm{F}=4.32, \mathrm{p}=0.01)$, family history of diabetes mellitus $(\mathrm{F}=2.67, \mathrm{p}=0.05)$, personal habits $(\mathrm{F}=2.37, \mathrm{p}=0.05)$, type of work $(\mathrm{F}=3.37, \mathrm{p}=0.05)$ and chronocity of illness $(\mathrm{F}=3.58$, $\mathrm{p}=0.05)$. [graph 2(a) \&(b)]

\section{CONCLUSION}

The study assessed the need of family focused intervention for diabetic clients, in which the knowledge regarding diabetes mellitus was assessed. The study findings showed that among rural people, knowledge was inadequate. The findings also proved that family focused nursing interventions are effective in improving the knowledge. Thus the family focused intervention can be incorporated as an integral component of the comprehensive health care services at primary level to enable the diabetic clients to manage the condition and prevent the complications.

\section{ACKNOWLEDGMENT}

I extend my sincere thanks to community level workers and key persons in the villages who helped me for the study. Also thank all the samples and their family members who participated in the study.

\section{REFERENCES}

[1]. World Health Organization. Global Report on diabetes. 2016.

[2]. WHO Global health report 2016

[3]. Seema Abhijeet Kaveeshwar and Jon Cornwall. The current state of diabetes mellitus in India. Australians Medical Journal. 2014 Page: 45-48.

[4]. International Diabetes Federation report. 2014.

[5]. Deepa. M, Bhanasali.A, Anjana. RM et.,al. Knowledge and awareness of diabetes in urban and rural India: The Indian Council of Medical Research India. Diabetes Study (Phase I). Indian Journal of Endocrinology and Metabolism. 2014. Volume:18. Page: 379-385.

[6]. Vijay Viswanathan and Samriddhi Ranjan. Diabetes An ancient disease, epidemic and an economic burden for the present era. Indian Journal of Medical Research. April 2016. Page No: 389-391.

[7]. Denise F. Polit and Cheryl Tatano Beck.Nursing Research. $8^{\text {th }}$ edition. Lippincott Williams and Wikins: Walters klwer (India) 2008 